\title{
Synthesis and Reactions of 2-(N-tetrabromophthalimido) Ethyl Acrylate Polymer with Hydroxy and Amino Compounds
}

\author{
A. A. Khalil \\ Chemistry Department, Faculty of Science, Benha University, \\ Benha, Egypt.
}

\begin{abstract}
V-(2-HYDROXYETHYL)tetrabromophthalimide (HETP) was prepared by heating tetrabromophthalic anhydride dissolved in dimethyl formamide (DMF) with ethanol amine. 2- $(\mathrm{N}-$ tetrabromophthalimido) ethyl acrylate (TPEA) was prepared by the reaction of acryloyl chloride (AC) with N-(2-hydroxyethyl) tetrabromophthalimide (HETP) in presence of triethyl amine(TEA). The resulting monomer was polymerized. The exchange reactions were carried out in solution at $60^{\circ} \mathrm{C}$ The structure of prepared polymers and copolymers was investigated by bromine analysis, IR and ${ }^{1}$ HNMR spectroscopy.
\end{abstract}

Keywords: N- (2- Hydroxyethyl ) tetrabromophthalimide, 2- ( Ntetrabromophthalimido) ethyl acrylate, Acryloyl chloride, Exchange reactions and Copolymers.

In the last few years, the control of the polymer production process has become especially important due to the increasing demands for specific qualities by industry as well as for their use in the environment and in medical practice. Recently, several activated polymers containing phthalimido moiety have been used as macromolecular drugs ${ }^{(1-4)}$. One of the most interesting topics in the field of pharmacologically active polymers is the preparation of polymeric drugs in which drugs are attached to the polymeric backbone via covalent bonds with limited stability to biological environments ${ }^{(5,6)}$. Activated esters of acrylic and methacrylic acids may be used as precursors of some classes of multifunctional polymers $^{(5)}$. This is due to the ability of many of them to react selectively with compounds bearing hydroxy or amino groups, giving esters or amidic bond, respectively, even in the presence of other chemical functions. For this reason, they provide a very convenient means for the preparation of some classes of macromolecular drugs ${ }^{(6)}$. Several activated esters and amides of acrylic and methacrylic acid and their polymers have been described ${ }^{(7-11)}$. In our previous work we described the synthesis, polymerization, copolymerization and exchange reactions of the acrylic and methacrylic esters of $\mathrm{N}$-hydroxyphthalimide and $\mathrm{N}$ hydroxytetrabromophthalimide ${ }^{(12-17)}$. The aim of the present work is to report the synthesis and polymerization of 2-(N-tetrabromophthalimido) ethyl acrylate (TPEA) as well as the exchange reactions of the resulting polymer with laminated and hydroxylated model compounds.

E-mail: aamkhalil@hotmail.com, Tel:+20124039232, Fax: +20133222578 


\section{Experimental}

\section{Materials}

Ethyl amine, pipredine, $\mathrm{p}$-anisidine, $\mathrm{p}$-toludine, $\mathrm{p}$-amino benzoic acid, $\mathrm{t}$ butanol, cyclohexanol, phenol, o-hydroxybenzoic acid and p-hydroxybenzoic acid were BDH (England) products. Acryloyl chloride and the free radical initiator, azobisisobutyronitril (AIBN), were from E.Merck, Darmstated. Tetrabromophthalic anhydride, triethylamine and ethanol amine were from Aldrich Co.. All the solvents were of reagent grade and were purified by distillation before use.

Synthesis

Synthesis of N-(2-hydroxyethyl)tetrabromophthalimide (HETP)

To $0.1 \mathrm{~mol}$ of tetrabromophthalic anhydride dissolved in $100 \mathrm{ml}$ of DMF, 0.1 mol of ethanolamine was added dropwise to it. The reaction was moderately exothermic, hence cooled in ice bath. The contents were stirred and heated in an oil bath to $130^{\circ} \mathrm{C}$ in nitrogen atmosphere for $4 \mathrm{hr}$. Excess DMF was removed by vacuum distillation and the contents were poured into water. The precipitated product was filtered off and recrystallized using ethanol as a solvent. The yield was $70 \%$ and m.p. was $268-270{ }^{\circ} \mathrm{C}$. Anal.: (Br\%,found $62.96 \%$, cal. 63.12), IR showed $v \mathrm{OH}$ at $3465 \mathrm{~cm}^{-1}$, $\mathrm{CO}$ at $1769,1707 \mathrm{~cm}^{-1}$ of coupling phthalimide and $v \mathrm{C}-\mathrm{Br}$ at $666 \mathrm{~cm}^{-1} .{ }^{1} \mathrm{HNMR}$ showed $-\mathrm{NCH}_{2}$ at $\delta 3.67,-\mathrm{OCH}_{2}$ at $\delta 3.41$ and $\mathrm{H}$ of $\mathrm{OH}$ at 84.78 .

Synthesis of 2-(N-tetrabromophthalimido)ethyl acrylate (TPEA)

2-(N-Tetrabromophthalimido)ethyl acrylate (TPEA) was prepared by the reaction of $\mathrm{N}$-(2-hydroxyethyl) tetrabromophthalimide (HETP) with acryloyl chloride in presence of triethyl amine (TEA). To a well-stirred cold solution $\left(0-5^{\circ} \mathrm{C}\right)$ of $\mathrm{N}$-(2-hydroxyethyl)tetrabromophthalimide (HETP) $(0.1 \mathrm{~mol})$, triethylamine $(0.1 \mathrm{~mol})$ in $150 \mathrm{ml}$ dry chloroform, acryloyl chloride $(0.1 \mathrm{~mol})$ was added dropwise. The reaction mixture was then allowed to stand at room temperature for $3 \mathrm{hr}$ and poured in excess petroleum ether $\left(40-60^{\circ} \mathrm{C}\right)$ to reprecipitate the triethylamine hydrochloride. After filtration, the filtrate was extracted with water to remove any residual triethylamine hydrochloride and evaporated to dryness in vaccum.The residue was then recrystallized from benzene/petroleum ether(20/80). The yield was $70 \%$ and m.p. was $160-162{ }^{\circ} \mathrm{C}$.

\section{Polymerization}

Solution $(10 \%)$ of the monomer in DMF was treated with azobisisobutyronitrile (AIBN) $(1 \mathrm{~mol} \%)$. After purging with deoxygenated nitrogen, the reaction mixture was allowed to stand at $60^{\circ} \mathrm{C}$ for $6 \mathrm{hr}$. The polymer was obtained by reprecipitation in methanol and were collected by filtration, washed, dried and weighted. The yield was $80 \%$.

Egypt. J. Chem. 54, No. 2 (2011) 


\section{Exchange reactions}

To a $10 \%$ solution of polymer in DMF, two equivalents of amine were added. The reaction mixture was allowed to stand at $60^{\circ} \mathrm{C}$ for $6 \mathrm{hr}$. Similarly, the exchange reactions with hydroxylated compounds were carried out except that the triethylamine ( 2 equivalents) was also added to the reaction mixture. In all cases, the products were isolated by pouring into an excess of diethyl ether, filtering, dissolving in DMF, reprecipitating with diethyl ether and drying.

\section{Characterization}

IR spectra were recorded $(\mathrm{KBr})$ on a Pye-Unicam Sp-883 Perkin Elmer spectrophotometer. ${ }^{1} \mathrm{H}$ NMR spectra were recorded on a Varian Gemini 200 $\mathrm{MHz}$ spectrophotometer, Cairo University. The chemical shift $(\delta)$ is given downfield relative to tetramethylsilian (TMS) as the internal standard. The elemental analysis were also carried out in Microanalytical Center, Cairo University.

\section{Results and Discussion}

In the present investigation, $\mathrm{N}$-(2-hydroxyethyl)tetrabromophthalimide (HETP) was prepared by heating tetrabromophthalic anhydride dissolved in dimethyl formamide (DMF) with ethanol amine according to the following scheme (Scheme 1):<smiles>CC(COCCN)C(F)(F)F</smiles>

Scheme 1<smiles>O=C1c2c(Br)c(Br)c(Br)c(Br)c2C(=O)N1CCO</smiles>

(II)

2-(N-Tetrabromophthalimido)ethyl acrylate (TPEA) monomer was prepared by the reaction of $\mathrm{N}$-(2-hydroxyethyl) tetrabromophthalimide (HETP) with acryloyl chloride in presence of triethyl amine according to the following scheme (Scheme 2): 
<smiles>C=CC(=O)Cl</smiles>

(I)

(II)<smiles>C=CC(=O)OCN1C(=O)c2c(Br)c(Br)c(Br)c(Br)c2C1=O</smiles>

Scheme 2

(III)

The monomer was a crystalline solid, easily soluble in most organic solvents, but sparingly soluble in aliphatic hydrocarbons such as n-hexane and petroleum ether. The monomer was readily polymerized in solution with azobisisobutyronitrile $(\mathrm{AIBN})$ as a free radical initiator. The polymer was soluble in DMF, DMSO, chloroform, acetone and dioxane and insoluble in water, benzene and ether.

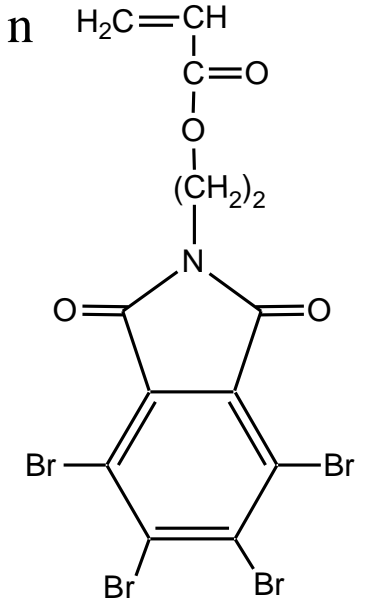

(III)

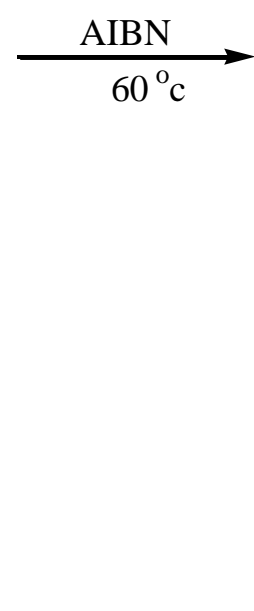<smiles>CCCC(=O)OCN1C(=O)c2c(Br)c(Br)c(Br)c(Br)c2C1=O</smiles>

(IV) 
The structure of 2-(N-tetrabromophthalimido)ethyl acrylate (TPEA) and poly-2-(N-tetrabromophthalimido)ethyl acrylate were established from IR and ${ }^{1}$ HNMR spectra (Table 1).

TABLE 1 . IR and ${ }^{1} \mathrm{H}$ NMR spectra of monomer (III) and its polymer (IV) .

\begin{tabular}{|c|c|c|c|c|c|}
\hline & & IR spectra & & & ${ }^{1} \mathbf{H}$ NMR \\
\hline Compound & $\begin{array}{c}v_{\mathrm{C}=\mathrm{O}} \\
(\text { ester }) \\
\mathrm{cm}^{-1}\end{array}$ & $\begin{array}{c}v_{\mathrm{C}=\mathrm{O}} \\
\text { (cyclic imide) } \\
\mathrm{cm}^{-1}\end{array}$ & $\begin{array}{l}v_{\mathrm{C}=\mathrm{C}} \\
\mathrm{cm}^{-1}\end{array}$ & Segment & $\begin{array}{r}\text { Chemical shift } \\
(\mathrm{ppm})\end{array}$ \\
\hline III & 1738 & 1840,1790 & 1620 & $\begin{array}{l}\mathrm{CH}_{2}=\mathrm{CH}- \\
\mathrm{CH}_{2}-\mathrm{N} \\
\mathrm{CH}_{2}-\mathrm{O}\end{array}$ & $\begin{array}{l}5.70-6.51 \\
3.90 \\
4.69\end{array}$ \\
\hline IV & 1740 & 1810,1785 & & $\begin{array}{l}-\mathrm{CH}_{2}-\mathrm{CH} \\
-\mathrm{CH}-\mathrm{CO} \\
-\mathrm{CH}_{2}-\mathrm{N} \\
-\mathrm{CH}_{2}-\mathrm{O}\end{array}$ & $\begin{array}{l}1.82 \\
2.65 \\
3.95 \\
4.75\end{array}$ \\
\hline
\end{tabular}

Reactions of polymer (IV) with amines

The ability of poly-2-(N-tetrabromophthalimido)ethyl acrylate (IV) to enter into an exchange reactions with amines was tested with ethylamine, pipridine p-anisidine, $p$-toludine and p-aminobenzoic acid. In a typical experiment, a $10 \%$ solution of polymer (IV) in DMF was treated with 2 equivalents of amine and the reaction mixture was allowed to stand at $60^{\circ} \mathrm{C}$ for $6 \mathrm{hr}$ (Scheme 4):

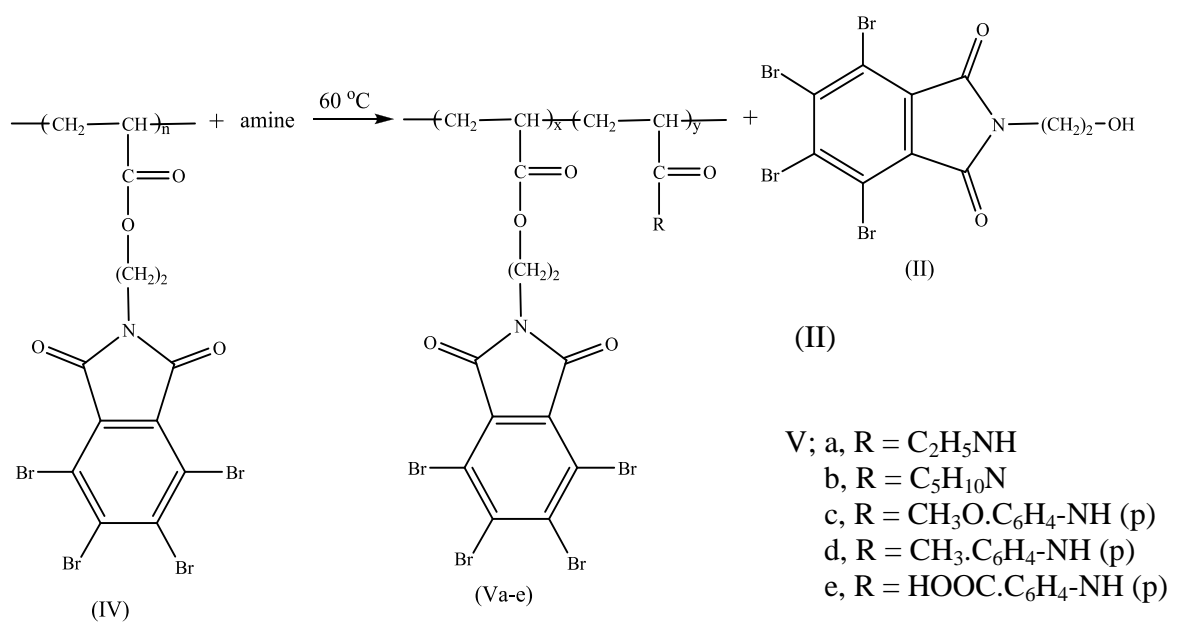

Scheme 4 
The percentage of the exchange reaction in each case was calculated from bromine analysis (Table 2). The structures of the produced polymers were established by IR spectroscopy. IR spectra of polymers (Va-e) show a strong band at about $3450-2600 \mathrm{~cm}^{-1}$ due to $-\mathrm{NH}$ and $-\mathrm{CH}$ stretching vibrations and strong bands at about $1630-1640 \mathrm{~cm}^{-1}$ and $1510-1530 \mathrm{~cm}^{-1}$ assigned to $v_{\mathrm{C}=0}$ (amide I and II), respectively. The structure of product (II) was established on the basis of IR data and a direct comparison (mmp) with an authentic sample ${ }^{(15)}$.

TABLE 2. Analytical data for the exchange reactions of polymer (IV) with amines.

\begin{tabular}{|l|c|c|c|}
\hline Co-reactant & Br\% & Exchange \% & Time(hr) \\
\hline Ethylamine & 17.75 & 93 & 6 \\
\hline Piperidine & 29.34 & 79 & 6 \\
\hline p-Anisidine & 15.22 & 90 & 6 \\
\hline p-toludine & 16.98 & 89 & 6 \\
\hline p-Aminobenzoic acid & 18.65 & 86 & 6 \\
\hline
\end{tabular}

$\mathrm{Br} \%$ for unexchanged polymer $=57.04$

Reactions of the polymer (IV) with hydroxy compounds

The ability of poly-2-(N-tetrabromophthalimido)ethyl acrylate (IV) for exchange reactions with hydroxy compounds was tested with t-butanol, cyclohexanol, phenol, o- and p-hydroxybenzoic acids (Scheme 5)

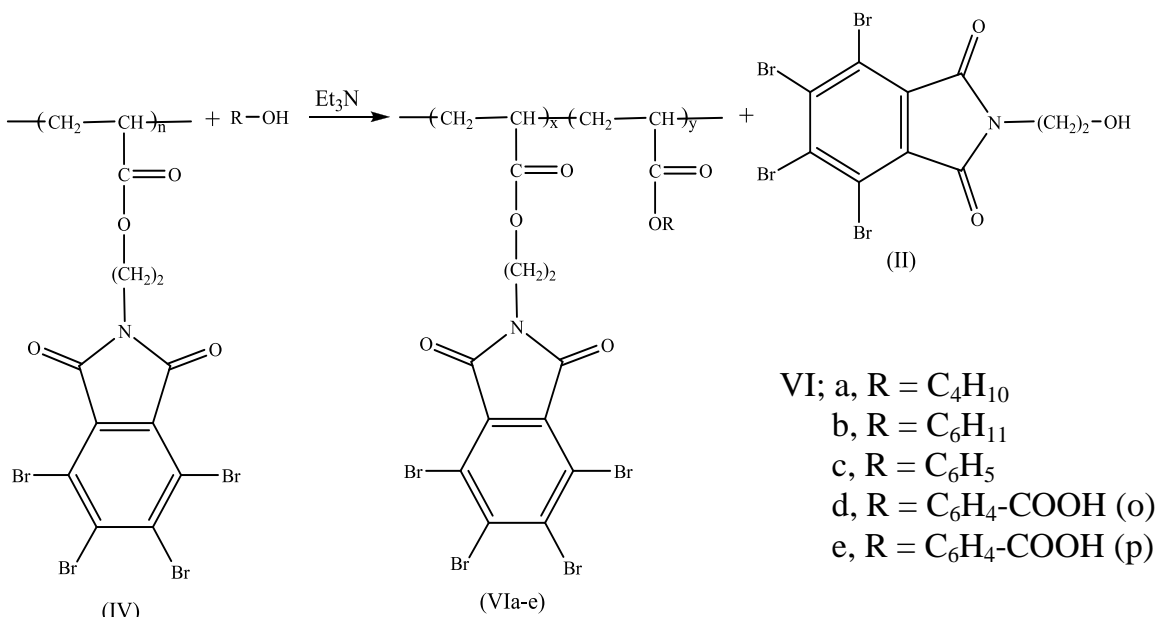

\section{Scheme 5}

All the above exchange reactions take place easily when a $10 \%$ solution of poly-2-(N-tetrabromophthalimido)ethyl acrylate (IV) was treated with two equivalents of a hydroxy compound and two equivalents of triethylamine and allowed to stand at $60^{\circ} \mathrm{C}$ for $6 \mathrm{hr}$ The results are summarized in Table 3 .

Egypt. J. Chem. 54, No. 2 (2011) 
TABLE 3. Analytical data for the exchange reactions of polymer (IV) with hydroxy compounds.

\begin{tabular}{|l|c|c|c|}
\hline Co-reactant & Br\% & Exchange\% & Time (hr) \\
\hline t-Butanol & 32.76 & 76 & 6 \\
\hline Cyclohexanol & 35.74 & 68 & 6 \\
\hline Phenol & 20.45 & 87 & 6 \\
\hline o-Hydroxybenzoic acid & 34.55 & 65 & 6 \\
\hline p-Hydroxybenzoic acid & 16.75 & 88 & 6 \\
\hline
\end{tabular}

The exchange reactions of poly-2-(N-tetrabromophthalimido) ethyl acrylate with cyclohexanol in DMF solution was further investigated. We were especially interested in cyclohexanol, because it is a model for studying polymeric adducts of steroid hormones and prostaglandins ${ }^{(18)}$.

For equivalent quantities of polymer, cyclohexanol and triethylamine, the progress of the reaction (6) (percent exchange) was recorded against the reaction time $(\mathrm{t})$ at $20^{\circ} \mathrm{C}$ and $60^{\circ} \mathrm{C}$. The results are reported in Tables 4 and 5. From Tables 4 and 5, it is clear that poly-2-(N-tetrabromophthalimido)ethyl acrylate showed a good behavior as a model compound for a long active polymeric-drug.

\section{Conclusion}

From the above data, it may be concluded that the new monomer described in this paper may be useful for the preparation of polymeric-drug addicts. Furthermore, similar monomeric phthalimides may be synthesized starting from a number of other hydroxy or amino acids, thus providing wider possibilities for the synthesis of pharmacologically active polymers.

TABLE 4. Analytical data for the exchange reactions of polymer (IV) with cyclohexanol at $20^{\circ} \mathrm{C}$ in presence of triethylamine.

\begin{tabular}{|c|c|c|c|}
\hline Polymer & $\begin{array}{c}\text { Reaction time } \\
\text { (days) }\end{array}$ & Br\% & Exchange\% \\
\hline IV & 1 & 54.38 & 16 \\
\hline & 2 & 51.31 & 29 \\
\hline & 4 & 49.02 & 44 \\
\hline & 8 & 44.15 & 73 \\
\hline & 12 & 40.03 & 81 \\
\hline
\end{tabular}


TABLE 5. Analytical data for the exchange reactions of poly-2-(N-phthalimido) ethyl acrylate (IV) with cyclohexanol at $60^{\circ} \mathrm{C}$ in presence of triethylamine.

\begin{tabular}{|c|c|c|c|}
\hline Polymer & $\begin{array}{c}\text { Reaction time } \\
(\text { min })\end{array}$ & Br\% & Exchange\% \\
\hline IV & 15 & 55.48 & 9 \\
\hline & 30 & 53.94 & 17 \\
\hline & 60 & 52.76 & 23 \\
\hline & 120 & 47.65 & 42 \\
\hline & 240 & 42.95 & 54 \\
\hline
\end{tabular}

References

1. Orzeszko, A., Gralewska, R., Starosciak, B.J. and Kazimierczuk, Z., Acta Biochemica Polonica, 47, 87 (2000).

2. Lee, N. J., Koo, J.C., Ju, S.S., Moon, S.B., Cho, W.J., Jeong, I.C., Lee, S.J., Cho, M. Y. and Theodorakis, E. A., Polym Int. 51, 569 (2002).

3. Lee, N.J., Ju, S. S., Cho, W.J., Kim, S.H., Kang, K.T., Brady, T. and Theodorakis, E. A., Polym Int. 52, 1339 (2003).

4. Lee, N. J. and Theodorakis, E.A., Macromol Res. 11, 47 (2003).

5. Cecchi, R., Rusconi, L., Tanzi, M.C., Danusso, F. and Ferruti, P., J. Med. Chem. 24, $622(1981)$.

6. Ghedini, N., Ferruti, P., Andrisano, V., Cesaroni, M.R. and Scapini, G., Synth Commun. 13, 701 (1983).

7. Ferruti, P. and Vaccaroni, F. J., Polym. Sci. Polym. Chem. Ed. 13, 2859 (1975).

8. Ferruti, P., Fere, A. and Cottica, G., J. Polym. Sci. Polym. Chem. Ed. 12, 533 (1974).

9. Ferruti, P., Vaccaroni, F. and Tanzi, M.C., J. Polym. Sci. Polym. Chem. Ed. 16, 1435 (1978).

10. Ferruti, P. and Cottica, G., J. Polym. Sci. Polym. Chem. Ed. 12, 2453 (1974).

11. Khalil, A. A., J. Appl. Polym. Sci. 121,1160 (2011)

12. Shaaban, A.F., Arief, M.M.H., Khalil, A.A. and Messiha, N.N., Acta Polym. 39, 145 (1988). 
13. Shaaban, A.F., Khalil, A. A. and Messiha, N. N., J. Appl. Polym. Sci. 37, 2051 (1989).

14. Shaaban, A.F., Khalil, A. A. and Messiha, N. N., Acta Polym. 40, 445 (1989).

15. Mahmoud, A.A., Shaaban, A.F., Khalil, A.A. and Messiha, N.N., Die Angew Makromol Chem. 198, 31 (1992).

16. Khalil, A.A., Moustafa, H.Y. and Arief, M.M.H., Eur. Polym. J. 32, 647 (1996).

17. Khalil, A. A. J. Appl.Polym.Sci. 99, 2258 (2006).

18. Ferruti, P., Paoletti, R. and Puglisi, R., Adv. Prostag. Thromb. Res. 1, 231 (1976).

(Received 1/ 8 /2011;

accepted $16 / 8 / 2011$ )

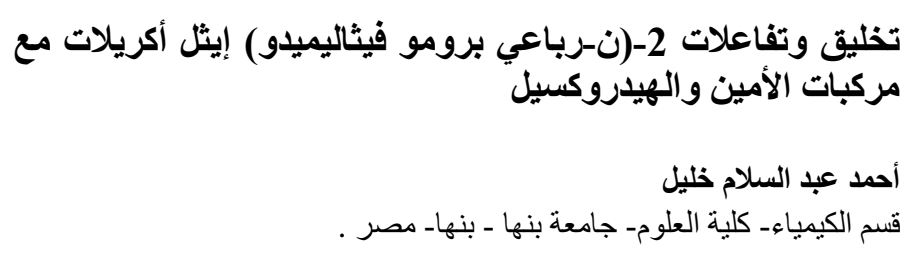

في هذا البحث تم تحضير ن-(2- هيدروكسي إيثيل ) رباعي برومو الفيثاليميد من إني

إضافة الإيثانول أمين إلى رباعي برومو أنهيدريد حمض الفي الفيثاليك في ثنائي ميثل

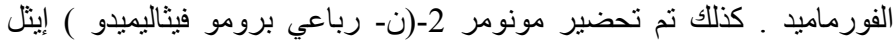

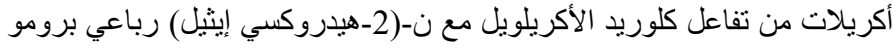

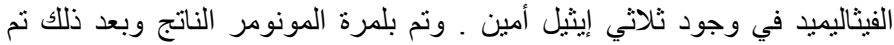

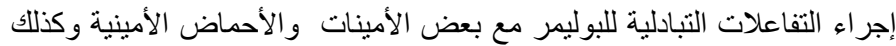

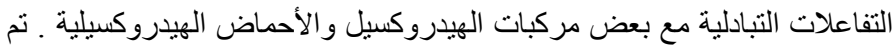

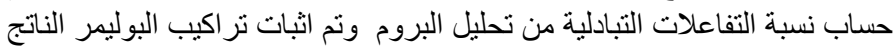

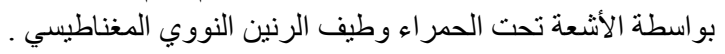

